\title{
FORMATIVE ASSESSMENT A RESEARCH BASED ON A TEACHERS' TRAINING COURSE IN A BLEARNING ENVIRONMENT
}

\author{
Ana Rocha, Maria Casanova, Lúcia Amante, Isolinda Oliveira, Lead.uab.pt, Portugal
}

\begin{abstract}
In this article we present a research project whose results are the outcome of a teachers' training course, for the practice of formative assessment, with the use of digital tools, applied to students from the third cycle, of basic education, to secondary education. Our key question, "How is formative assessment put into practice in the classroom of the teachers involved in our training workshop?", stemmed from the following core objectives: understanding if teachers integrate the technological dimension into the design of their students' assessment and perceiving the sort of digital tools they use to promote teaching and the regulation of the students' learning. The focus of our training course, developed as a workshop, was to understand how the teachers' practices had changed after attending the course. The study was developed as a qualitative and interpretive research and the teachers' training plan was elaborated in an action-research model. The collected data was triangulated from multiple sources in order to capture the complex and multi-faceted aspects of the pedagogical work. The results offered evidence of the potentialities and constraints of the students' formative assessment, grounded on digital learning platforms, and the ways teachers incorporate certain digital tools into their practices.
\end{abstract}

Keywords: Formative assessment; Digital assessment; Teacher training;

\section{Introduction}

In the current study we wanted to characterize the teachers' assessment practices in the classroom and intervene in their pedagogical exercise so as to bring about an enhancement. Having this purpose in mind we developed an in service teacher training plan, using a blended learning model, which combined digital contexts with a conceptual matrix and framework for the assessment of competences.

The research was developed in an action-research methodology as a qualitative and interpretive approach. We established the following objectives: (a) understanding if the 
students' assessment is intentionally and unequivocally formative; (b) clarifying whether the participant teachers of the third cycle and secondary education include online tools when the students' assessment, and learning, is designed and executed; and (c) identifying which are the most common digital tools used in the students' learning and assessment processes. In the action-research technique we aimed at leading the participants into a deep reflection about their pedagogical performance, and guiding their teaching processes into an active incorporation of formative assessment in a digital environment. During the teachers' training sessions we intentionally carried out improvement strategies for the incorporation of digital tools on formative assessment procedures.

This paper is focused in presenting the blended learning and training plan design in which collaborative social constructivist practices were adopted.

\section{What is a Digital Formative Assessment?}

Formative assessment, which is digital, occurs in a domain that is not geographically located, using the dynamics of collaborative work and digital technologies online. It is practiced in a virtual learning environment, integrates the references of non-digital formative assessment, and is mediated pedagogically by the teacher, in a multidirectional cooperative structure in which students are proactive actors, interacting with each other and with the teacher. This means, according to Pereira, Oliveira, Tinoca, Pinto, and Amante (2015; p.11) that it should be an assessment for learning, through the adoption of an approach in which the student is seen as an active participant, who shares responsibility for the learning process, practices self-assessment and reflection, and collaborates with the teacher and with the other students.

The activities undertaken by teachers, and / or by students, in a formative assessment, whether being digital or without the use of online platforms, provide information, that should be used to give feedback, in order to orient the teaching and learning activities involving the students. Emphasizing this principle, of a feedback which has to be considered a feedforward, we have selected the following description that seems to clearly define the way we understand it:

"An assessment functions formatively to the extent that evidence about student achievement is elicited, interpreted, and used by teachers, learners, or their peers to make decisions about the next steps in instruction that are likely to be better, or better founded, than the decisions they would have made in the absence of that evidence" (Wiliam, 2011; p.43).

To make the learners recognize the added value of digital formative assessment, as a needed strategy which can develop their intellectual capacities and cognitive processes - 
targeted through the analysis, planning and implementation of the necessary actions to obtain success (Salema \& Cardoso, 2015) - it is essential that the design of this assessment fits into some quality standards, is mediated by technologies, and built around four main dimensions: authenticity, consistency, transparency and practicality (Pereira, Oliveira, Tinoca, Pinto, \& Amante, 2015). These dimensions are, to some degree, an assurance that the online assessment tasks are complex, related to a real life context, and recognized as significant by students, teachers and all the involved in the process (Figure 1).

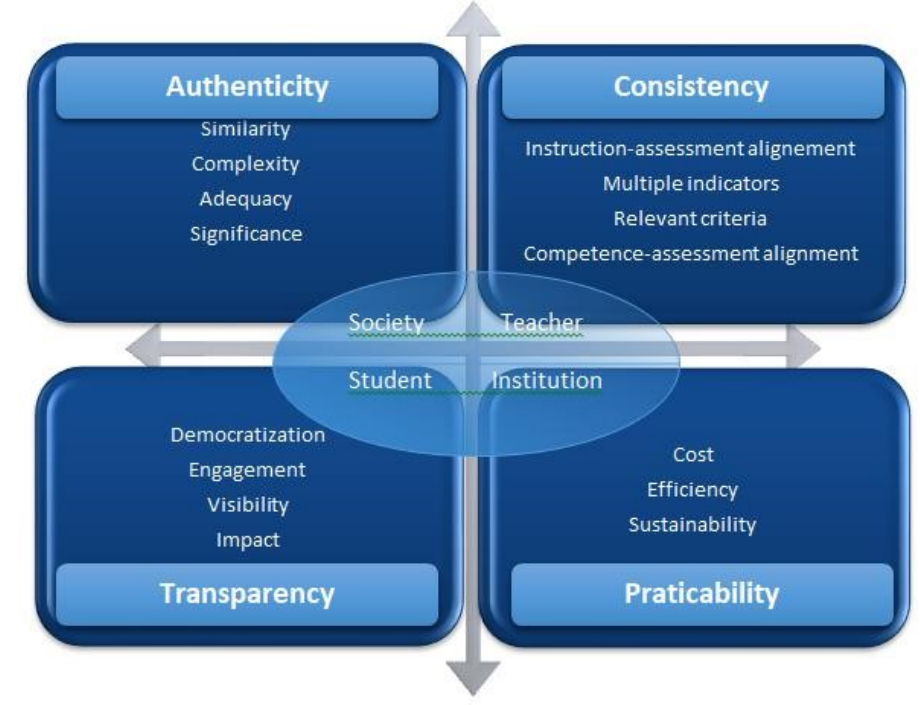

Figure 1. Framework for the assessment of competences in digital assessment (Pereira, Oliveira, Tinoca, Pinto, \& Amante, 2015)

Even if this conceptual matrix was originally developed for e-assessment in Higher Education, it was applied as a framework, in our research, in the in service training course. A more complete and detailed description of the dimensions, and their reference criteria, should be looked up at Pereira, Oliveira, Tinoca, Pinto, and Amante (2015). The following description is a summary:

- Authenticity - is related to the degree of similarity between the competences being assessed and the ones required in real life. In this dimension four reference criteria, contributing to the degree of assessment authenticity, are included: Similarity, Complexity, Adequacy, and Significance.

- Consistency - it has the teacher as a main referent and requires the alignment of the competences, under assessment, with the instructional tasks, assigned to the students, the strategies, used in the teaching process, and the assessment criteria, which should have varying indicators. The dimension is constituted by four criteria: Instruction-assessment alignment, Multiplicity of indicators, Relevant criteria and Competences-assessment alignment.

- Transparency - it presents the student as a referent and points out to the need for digital assessment to be perceived as fair, by all the involved. Therefore, it requires 
full knowledge of the criteria and their relative weights. For this dimension, four criteria were contemplated: Democratization, Engagement, Visibility, and Impact.

- Praticability - it is related with the feasibility of the assessment strategy and has the school as a referent. It implies an effective management, and balance, between time and cost/efficiency. If practicability is guaranteed the students consider the assessment strategies as being relevant, doable, and a real contribution to their learning. It is comprised of three criteria: Costs, Efficiency and Sustainability.

\section{The relevance of teacher training in a bLearning model for the practice of digital assessment}

If trainee teachers are asked to understand the importance of the inclusion of a formative assessment into their classrooms, incorporating strategies hosted by digital environments which are not exclusively psychometric, they have to be guided into the performance of experiences which are transferable to their real practice. Additionally, their performance should be made consistent and in balance taking into consideration the purposes of the curriculum, the teaching and the assessment (Fernandes, 2008; p.78). This means the training circumstances ought to resemble learning contexts, similar to a didactic intervention with students.

When teacher training sessions juxtapose practices, which the teachers can replicate with their students, they are better recognized as enriching training environments where the answers, to their greatest difficulties, are found, especially because the adoption of an active blended learning paradigm is not yet totally established in the classrooms routines. In a formative model of this nature, the combination of different technologies and learning configurations include sequences of synchronous and asynchronous work, facilitated by digital web tools, among other conventional means of training support. The trainer, in the role of a facilitator, selects the strategies that best suit the trainees' personal characteristics and digital literacy level. As a coach, establishes a favourable relationship, handling the moments something has to be said, and theoretical arguments have to be presented, with those in which he must be a dynamic listener. Now and then he demonstrates, and, in other moments, the trainees reproduce or create. The trainer must keep questioning the processes and deciding what is more appropriate for the participants. An in service training course has to be meaningful, pertinent, contribute to the reconstruction of the knowledge already acquired and take advantage of the trainees' previous experiences, stimulating the research of problems on the teachers own practice (Rocha, 2013; p.197).

It's unavoidable that teachers acquire updated digital skills. Many teachers are still afraid of using educational software and strife with online pedagogy. In covid-19 times, of distance learning emergency plans, the classrooms had to be brought into a virtual space 
and these unfamiliar circumstances have posed new challenges, particularly, with communication technologies and online platforms, treading the path to develop the learners' competences. The current urgency for the development of digital and technological skills, and online expertise, is making distance education, in training courses, more and more relevant. New training opportunities should provide collaborative spaces to promote knowledge and critical reflection, in order to help teachers build new bridges so that their comfort zone becomes familiar again and is re-established. In a sense, we agree with Dewey (1988; p.134) "to learn from experience is to make a backward and forward connection [...] doing becomes a trying; an experiment with the world to find out what it is like". We now have a more fertile field than before, when, in the classroom, traditional teaching models were practiced. More dynamic and innovative training environments may contribute to more motivating teaching practices.

Consequently, it seems essential that the training sessions offer experiences and learning perspectives to think, analyse, evaluate, as well as, opportunities to create and for individual development and professional enhancement, by means of a collective support.

\section{Methodology}

We took a qualitative approach, using a variety of information sources, combining quantitative and qualitative methods, through the application of two surveys, participant observation, field notes (collected during the training sessions) and narratives (included in digital portfolios - in this paper we'll be fixated in the results of the surveys as it won't be possible to mention the data collected from the other sources). We considered that it is advantageous to collect quantitative and qualitative data, taking Flick (2004) as a reference, as it allows the convergence of interpretations, mutual confirmation and support for the conclusions. On the other hand, the triangulation of all data establishes the guarantee of internal validity, being relevant in the context of a good qualitative study, as pointed out by Yin (1994) or Stake (1995).

The surveys had the specific intention of obtaining the participants' know-how in formative assessment and if their practices had changed (or not), in the outcome of the course, in comparison with the entry point. They had similarities, were made on a Likert scale, containing three open questions, and were applied in the pre-initial and post-final moment of the training. The pre-survey, of an exploratory nature, made it possible to identify the pattern, most commonly adopted by teachers, in the students' formative assessment. We also perceived whether their formative assessment choices were intentionally and unequivocally formative, included a technological design and which digital tools the participant teachers were already familiarised with. The follow-up survey aimed at ascertaining the degree of understanding of the participants about a real 
formative assessment; whether they had evolved in their comprehension of the theoretical grounds; and it they had acquired a more assertive position on the positive evidences of using digital tools in a blearning pedagogy. The preliminary results offered evidence of their practices of an incipient nature, including formative assessment with a low expression in the didactics and revealing many similarities with a summative assessment.

In the training sessions we stimulated group work, by departmental affinities, and continuous interaction between the trainees-trainers and trainees-trainees. It was made clear that these affinities facilitated the convergence of interests and the development of common tasks with main purposes.

Figure 2 is an illustration of the sequential structure of the workshop, demonstrating how the face-to-face sessions were coordinated with the non-face-to-face moments, according to a pedagogical architecture that stimulated the learning pursuit.

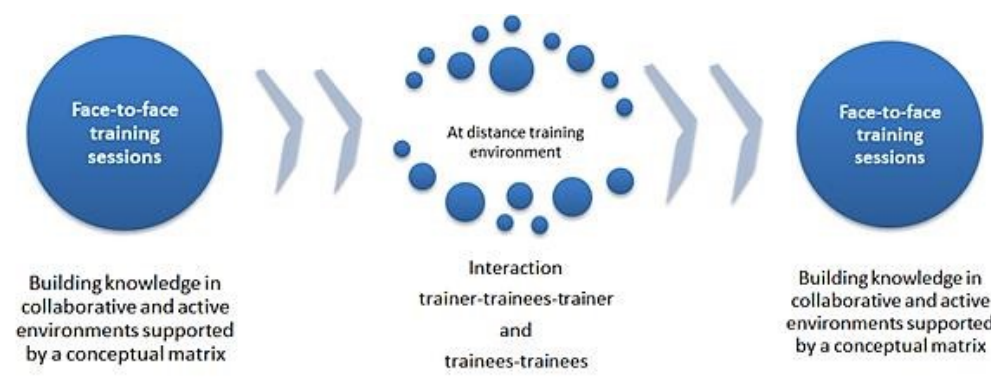

Figure 2. Blearning Training design

The contents of the action were distributed according to the following plan:

19. Formative assessment and learning a. The diagnosis of training needs.

- Theoretical foundation:

○ Clarification of concepts

○ Framework for a formative assessment

- Presentation of the training tasks with the Moodle support

20. Practical activities for building assessment instruments and tools in a digital environment

- Adaptive preliminary elearning activities for the training work model

- Activities related with the digital assessment theoretical framework

- Design of the formative assessment instruments for application in the classroom

- Peer assessment strategies.

21. Follow up activities

- Assessment of the learning carried out in the context of the workshop. 
- Sharing experiences.

- Workshop assessment.

During the workshop tasks, we incorporated frequent feedback dynamics, as well as the dimensions and criteria which had to be considered in the design of the digital formative assessment (authenticity, consistency, transparency and practicality). Similarly, we requested that the activities, developed by the trainees in the execution of the students' formative assessment, included them.

The thirteen participants, nine female and four male teachers, teaching in the $3^{\text {rd }}$ cycle and in secondary level classrooms, had diverse disciplinary contexts (Arts, Biology and Geology, English, Sciences, Geography, Economics and ICT). They were aged between 41 and 55 years old and each one was teaching a diversity of classrooms. They chose one or two classrooms to be the target of their improvement intervention in the context of the training workshop. The number of students which were reached and involved in these teachers' in service training strategies, mounted to a total of 364.

The face-to-face sessions favoured the gradual adaptation to the tasks in a digital environment considering that the trainees manifested having different skills in the use of technologies, and demonstrated unlike familiarity levels with distance learning or teaching.

\section{Results}

The training workshop, which we designed to be the case of the study, was planned in order to provide the participants with a diversity of experiences, digital tools and practical activities, for building assessment mechanisms in an online environment. The practical autonomous work, consisting of the conception of formative assessment instruments, to apply in the classroom, had to be designed in line with the digital assessment framework. These initiatives made it possible to understand the constraints and potential aspects of using assessment for learning, based on the suggested digital platforms. After their effective use with the students, associating innovative opportunities for online collaboration, promoting self-assessment and hetero-assessment and performing feedback initiatives, the participant teachers had the opportunity to reflect in groups and offer their points of view on the benefits of the learning which was acquired.

Confronting the collected data in the two surveys, pre and follow-up, the impact of our training initiatives were made clear, as they resulted in interesting indicators about the intention of proceeding on with a blearning pedagogical method for the formative assessment of the students. 


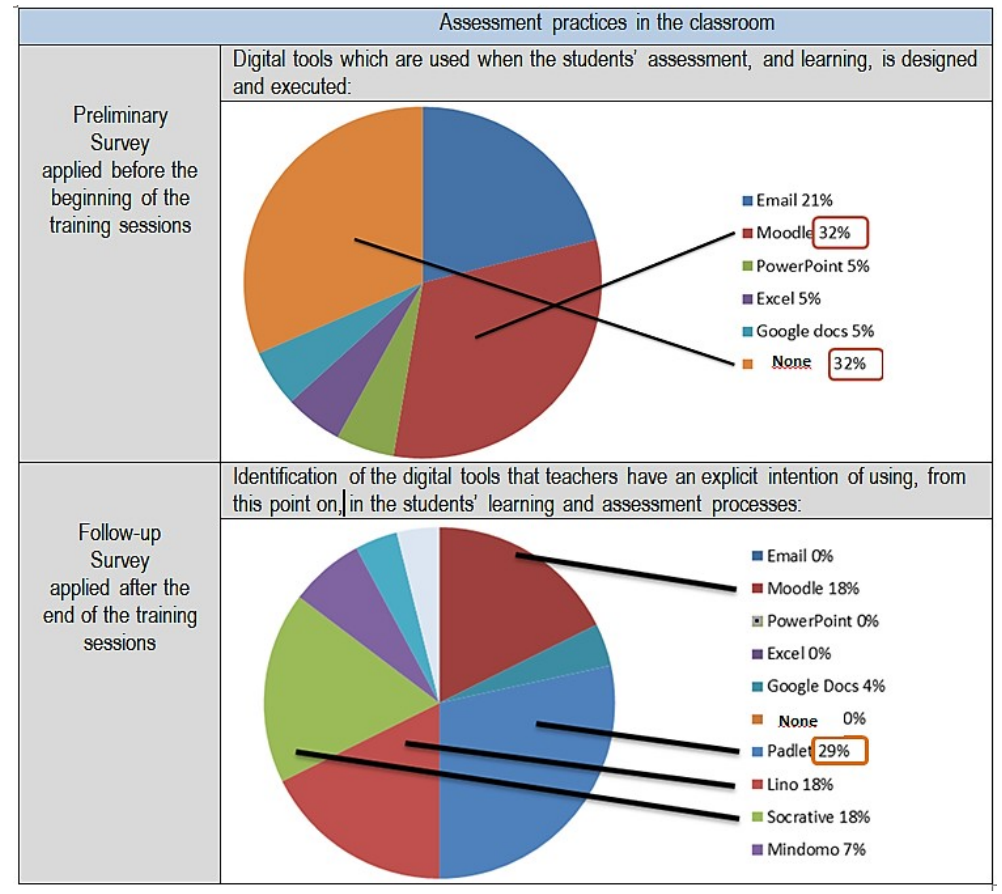

Figure 3. Digital tools in formative assessment and feedback strategies

In Figure 3 it can be observed how teachers recognized the potential of integrating the technological dimension in assessment situations. In addition to being more captivating for students, a digital learning environment promotes a greater intervention and awareness of the student in the assessment process and, consequently, in their school trajectory. After having attended the training workshop, the participant teachers seem to reveal a renewed intention to regulate the students' learning, by means of dynamic and interactive digital environments.

\section{Conclusion}

At the beginning of the study, and before the training sessions had started, we collected data on practices that incorporated, in an insignificant way, the use of wikis for collaborative work, and, apparently, in a more intentional way, the Moodle platform, or Google docs. The Email, PowerPoint, Excel, or a class blog, were also pointed out as digital tools which were being used in the regulation of learning and in the elaboration of feedback. However, we found out that this practice, although framed in an intention of formative assessment, did not include individualized and descriptive elements and was centred on sending materials or disseminating results to the class group. These digital tools were, therefore, used for sharing or depositing materials. It seemed that digital environments were carried out, occasionally, without truly integrating the teaching and learning process. It was an incipient or embryonic technological use.

The training plan, that we implemented, intentionally guided and capacitated teachers to start designing teaching and learning processes, which include a technological dimension. 
Our aim was also the promotion of higher-level cognitive processes during the performance of tasks. At the end the respondents clearly indicated having benefited from the provided hands-on course, as they were able to improve the characteristics of their pedagogical methods.

Web technologies may assist and promote innovative models of formative assessment and can foster the students' critical sense and initiative. In contexts of a digital nature it is possible to generate a cooperative and collaborative learning, projecting the teacher to the role of a guide and advisor in the student's autonomy. Pedagogical differentiation and inclusion, resulting from blearning educational structures which are adjusted to the student's profile, favour the flourishing of students. They also lead them into the development of $21^{\text {st }}$ century skills, as pointed out in the report by Schleicher (2012).

\section{References}

Amaral, M. J., Moreira, M. A., \& Ribeiro, D. (1996). O Papel do Supervisor no Desenvolvimento do Professor Reflexivo. Estratégias de Supervisão. In I. Alarcão (Ed.), Formação Reflexiva de Professores. Estratégias de Supervisão (pp. 89122). Porto: Porto Editora.

Dewey, J. (1988). Democracy and education. New York: Free Press.

Fernandes, D. (2008). Avaliação das Aprendizagens: Desafios às Teorias, Práticas e Políticas. Lisboa: Texto Editores.

Flick, U. (2004). Introducción a la investigación cualitativa. Madrid: Morata.

Pereira, A., Oliveira, I., Tinoca, L., Pinto, M., \& Amante, L. (2015). Desafios da avaliação digital no Ensino Superior. Lisboa: Universidade Aberta.

Rocha, A. P. (2014). Dispersão da Atividade Docente. O Poder do Professor Reflexivo Crítico num Contexto Formativo Colaborativo. Tese de Doutoramento (Doutoramento em Educação). Lisboa: Universidade de Lisboa.

Salema, L., \& Cardoso, T. (2015). Cultura participatória e avaliação: Desafios para uma avaliação digital participatória. In A. P. T. Cardoso (Ed.), Avaliação e Tecnologias no Ensino Superior (pp. 22-37). Lisboa: Universidade Aberta.

Schleicher, A. (2012). Preparing Teachers and Developing School Leaders for the $21^{\text {st }}$ Century: Lessons from around the World. OECD Publishing.

Stake, R. E. (1995). The art of case study research. California, London, New Delhi: SAGE Publications.

Wiliam, D. (2011). Embedded formative assessment. Bloomington, IN: Solution Tree Press. 
Rocha, A., Casanova, M., Amante, L., \& Oliveira, I.

Formative Assessment a Research based on a Teachers' Training Course in a bLearning Environment

Yin, R. (1994). Case study research: Design and methods. Thousand Oaks, CA: SAGE Publications. 